\title{
Randomised, double blind trial of two loading dose regimens of diamorphine in ventilated newborn infants
}

\author{
D P Barker, J Simpson, M Pawula, D A Barrett, P N Shaw, N Rutter
}

\begin{abstract}
Aims-To compare the safety and efficacy of two loading doses of diamorphine in 27 ventilated newborn infants in a randomised double blind trial. Methods-Fifty or $200 \mathrm{mcg} / \mathrm{kg}$ were infused intravenously over 30 minutes, followed by a $15 \mathrm{mcg} / \mathrm{kg} / \mathrm{hour}$ continuous infusion. Serial measurements were made of physiology, behaviour, and stress hormones.

Results-Both loading doses produced small but significant falls in blood pressure. The $200 \mathrm{mcg} / \mathrm{kg}$ dose produced greater respiratory depression, and two infants deteriorated clinically, requiring resuscitation. Loading reduced respiratory effort in most of the infants, but had little effect on behavioural activity. Stress hormone concentrations were reduced at six hours in both dosage groups; differences between loading doses were not significant. Morphine, morphine-3glucuronide, and morphine-6-glucuronide were detected in the plasma of all patients. No significant differences in concentrations between loading doses were found. Conclusions-Diamorphine reduces the stress response in ventilated newborn infants. A high loading dose confers no benefit, and may produce undesirable physiological effects. A $50 \mathrm{mcg} / \mathrm{kg}$ loading dose seems to be safe and effective.
\end{abstract} (Arch Dis Child 1995; 73: F22-F26)

Keywords: analgesia, morphine, diamorphine, loading dose.

Opiate sedation and analgesia have been advocated for newborn infants receiving intensive care, ${ }^{12}$ but the optimal agent and dose have not been defined. In view of potentially harmful side effects a thorough evaluation of the safety and efficacy of opiates is important before their use becomes widespread. ${ }^{3}$

Diamorphine (3,6-diacetylmorphine) is a semi-synthetic morphine derivative that is

Table 1 Characteristics of the infants studied with median (interquartile range)

\begin{tabular}{lcc}
\hline & $50 \mathrm{mcg} / \mathrm{kg}$ loading dose $(n=13)$ & $200 \mathrm{mcg} / \mathrm{kg}$ loading dose $(n=14)$ \\
\hline Gestation (weeks) & $29(27-30)$ & $29(27-32)$ \\
Birthweight (kg) & $1 \cdot 30(1 \cdot 09-1 \cdot 69)$ & $1 \cdot 22(1 \cdot 12-2 \cdot 02)$ \\
Caesarean delivery & 9 & 11 \\
Apgar score & $4(3-7)$ & $5(3-6)$ \\
$\quad$ Minute & $8(6-9)$ & $8(6-9)$ \\
$\quad$ Minutes & $15(6-22)$ & $23(6-37)$, \\
Age at entry (hours) & & \\
\hline
\end{tabular}

rapidly metabolised to morphine. It is used by almost a third of newborn intensive care units in the United Kingdom. ${ }^{4}$ A previous study concluded that a $50 \mathrm{mcg} / \mathrm{kg}$ intravenous loading dose, followed by a $15 \mathrm{mcg} / \mathrm{kg} / \mathrm{hour}$ infusion, was safe, although efficacy was not assessed. ${ }^{5}$ Plasma morphine concentrations in this study were comparable with those reported to produce effective analgesia in children and adults. However, a delay of several hours occurred before such levels were reached. It was predicted, using a pharmacokinetic model, that a loading dose of $200 \mathrm{mcg} / \mathrm{kg}$ would result in effective and steady-state plasma morphine concentrations within one hour of starting treatment. 6

A randomised, double blind study was therefore performed to compare 50 and 200 $\mathrm{mcg} / \mathrm{kg}$ loading doses. Serial physiological, behavioural, and hormonal measurements were made to assess safety and efficacy. Plasma samples were collected for the measurement of morphine, morphine-3-glucuronide, and morphine-6-glucuronide concentrations.

\section{Methods}

Twenty seven infants of gestational age 24 to 42 weeks (median 29 weeks) and birthweight 0.68 to $3.90 \mathrm{~kg}$ (median $1.24 \mathrm{~kg}$ ) were studied. Age at starting treatment ranged from 3 to 60 hours (median 16 hours). Fourteen infants were allocated the higher and 13 the lower loading dose. One infant allocated to the higher dose regimen deteriorated clinically during loading and did not receive the subsequent infusion. Data available from this infant were therefore incomplete, but those collected were analysed on an intention-to-treat basis.

The dosage groups were similar in gestation, birthweight, mode of delivery and condition at delivery (table 1). Hyaline membrane disease was the primary diagnosis in $23(85 \%)$ infants, of whom 20 received surfactant therapy. In the lower loading dose group one infant required ventilation for meconium aspiration, and in the higher loading dose group two infants had a primary diagnosis of hydrops, and one a diagnosis of hypoxic ischaemic encephalopathy.

Infants receiving the higher loading dose were less ill at study entry (table 2). They had significantly higher arterial oxygen concentrations and arterial:alveolar oxygen (a:A) ratios. Arterial $\mathrm{pH}$ and carbon dioxide tensions were also better, and age at study entry was greater, although these differences were not significant.

Several infants received dopamine during the study. One infant in the low loading dose group 
Table 2 Clinical data at study entry with median (interquartile range)

\begin{tabular}{lcc}
\hline & $50 \mathrm{mcg} / \mathrm{kg}$ loading dose & $200 \mathrm{mcg} / \mathrm{kg}$ loading dose \\
\hline Mean blood pressure (mm Hg) & $34(30-43)$ & $35(31-43)$ \\
Heart rate (bpm) & $157(141-162)$ & $144(127-159)$ \\
pH & $7 \cdot 29(7 \cdot 21-7 \cdot 35)$ & $7 \cdot 33(7 \cdot 25-7 \cdot 35)$ \\
$\mathrm{PCO}_{2}(\mathrm{kPa})$ & $5 \cdot 40(4 \cdot 95-6 \cdot 32)$ & $5 \cdot 25(4 \cdot 60-5 \cdot 80)$ \\
$\mathrm{PO}_{2}(\mathrm{kPa})$ & $6 \cdot 10(5 \cdot 75-6 \cdot 95)$ & $8 \cdot 40(7 \cdot 10-9 \cdot 70)^{\star \star}$ \\
a:A ratio & $0 \cdot 084(0 \cdot 081-0 \cdot 110)$ & $0 \cdot 147(0 \cdot 111-0 \cdot 245)^{\star}$ \\
\hline
\end{tabular}

${ }^{\star} \mathrm{P}<0.05 ;{ }^{\star \star} \mathrm{P}<0.005$ (Mann Whitney U-test).

and two in the high loading dose group were receiving dopamine at entry. One infant in each group started treatment between entry and six hours, and three in each group from six to 24 hours. Pancuronium was given to one infant in each group, but neither received this during the first 12 hours of diamorphine treatment.

Infants eligible to enter the study were those receiving mechanical ventilation, regardless of gestation or indication, who had not previously received opiates, and who did not require surgery. An indwelling arterial line was required for sampling and continuous blood pressure monitoring. In about two thirds of infants who fulfilled these criteria over the study period a decision was made by the clinical team to start diamorphine treatment. This decision was based on the amount of ventilatory support required and the infants' perceived level of distress, as judged by spontaneous activity and responses to handling and procedures. Infants were randomly allocated to receive either the higher or lower loading dose. Trial syringes were prepared by the hospital pharmacy, which held the code to their contents, and contained diamorphine in concentrations of 50 or $200 \mathrm{mcg} / \mathrm{ml}$. The loading dose was administered by drawing up the equivalent of the infants' weight in $\mathrm{kg}$ as mls of trial solution, diluting this to a total of $5 \mathrm{ml}$ with $5 \%$ dextrose and infusing the resulting solution intravenously over 30 minutes via a syringe pump. Neither the clinical team nor researchers were aware of which loading dose had been allocated, this information being available on request only to the consultant responsible for the study. After loading, a continuous infusion of $15 \mathrm{mcg} / \mathrm{kg} /$ hour diamorphine was started, which was adjusted as required by the clinical team. Recordings of blood pressure, heart rate, ventilator settings, and blood gases were made at study entry, after completion of the bolus infusion (30 minutes), and subsequently at two, six, 12 , and 24 hours. In addition, at each of these times the infants' behaviour and respiratory effort were assessed separately by one of two researchers using a simple scoring system (appendix 1). Blood samples (1 ml) were taken for measurement of cortisol, ${ }^{7}$ adrenaline, and noradrenaline ${ }^{8}$ at study entry, six, and 24 hours. A $0.5 \mathrm{ml}$ sample was collected for morphine, morphine-3-glucuronide (M3G), and morphine-6-glucuronide (M6G) analysis ${ }^{9}$ at the following times: before loading; immediately after loading; and at two, six, 12, and 24 hours, and at 24 hour intervals on subsequent days during the continuous infusion. Samples were centrifuged and the separated plasma stored at $-25^{\circ} \mathrm{C}$ until assayed.

Approval for the study was obtained from the hospital ethical committee, and written parental consent was obtained for each infant before randomisation.

\section{Results}

Administration of the loading dose resulted in a small but significant reduction in mean blood pressure in both groups (table 3), but changes in heart rate were not significant in either group. In the $200 \mathrm{mcg} / \mathrm{kg}$ dosage group arterial $\mathrm{pH}$ fell substantially due to carbon dioxide retention, and a simultaneous fall in arterial $\mathrm{PO}_{2}$ occurred. Changes in blood pressure (both groups) and blood gases $(200 \mathrm{mcg} / \mathrm{kg}$ group) had largely returned to baseline by two hours (table 4).

Two infants reacted adversely during infusion of the higher loading dose and required resuscitation. They were of similar gestation (27 and 28 weeks), birthweight (1.12

Table 3 Physiological changes (0-30 minutes) showing median (interquartile range)

\begin{tabular}{llll}
\hline & $50 \mathrm{mcg} / \mathrm{kg}$ loading dose & $200 \mathrm{mcg} / \mathrm{kg}$ loading dose & $\begin{array}{l}\text { Significance } \\
\text { (Mann-Whitney U test) }\end{array}$ \\
\hline Mean blood pressure (mm Hg) & $-2(-1 \text { to }-3)^{\star}$ & $-2.5(-1 \text { to }-6)^{\star \star}$ & $\mathrm{N} / \mathrm{S}$ \\
Heart rate $(\mathrm{bpm})$ & $0(+3$ to -10$)$ & $-6(-1$ to -9$)$ & $\mathrm{N} / \mathrm{S}$ \\
pH & $-0.02(-0.008 \text { to }-0.032)^{\star \star \star}$ & $-0.075(-0.05 \text { to }-0.09)^{\star \star}$ & $\mathrm{P}<0.005$ \\
$\mathrm{PCO}(\mathrm{kPa})$ & $+0.15(-0.025 \text { to }+0.54)^{\star}$ & $+0.80(+0.35 \text { to }+1 \cdot 20)^{\star \star \star}$ & $\mathrm{P}<0.05$ \\
$\mathrm{PO}_{2}(\mathrm{kPa})$ & $0.00(-1.15$ to $+1 \cdot 15)$ & $-2.05(-0.20 \text { to }-4 \cdot 6)^{\star}$ & $\mathrm{P}<0.05$ \\
a:A ratio & $-0.004(+0.002$ to -0.023$)$ & $-0.072(-0.050 \text { to }-0.099)^{\star \star \star}$ & $\mathrm{P}<0.005$
\end{tabular}

${ }^{\star} \mathbf{P}<0.05,{ }^{\star \star} \mathbf{P}<0.01,{ }^{\star \star \star} \mathbf{P}<0.005$ (Wilcoxon signed rank test).

Table 4 Physiological variables showing median (interquartile range)

\begin{tabular}{llllll}
\hline $\begin{array}{l}\text { Time } \\
\text { (hours) }\end{array}$ & $\begin{array}{l}\text { Heart rate } \\
\text { (bpm) }\end{array}$ & $\begin{array}{l}\text { Mean blood pressure } \\
(\mathrm{mm} \mathrm{Hg})\end{array}$ & Arterial $\mathrm{pH}$ & $\mathrm{PaO}_{2}(\mathrm{kPa})$ & $\mathrm{PaCO}(\mathrm{kPa})$ \\
\hline $50 \mathrm{mcg} / \mathrm{kg}$ loading dose & & & & \\
0 & $157(141-162)$ & $34(30-43)$ & $7 \cdot 29(7 \cdot 21-7 \cdot 35)$ & $6 \cdot 10(5 \cdot 75-6 \cdot 95)$ & $5 \cdot 40(4 \cdot 95-6 \cdot 32)$ \\
$0 \cdot 5$ & $147(139-158)$ & $31(29-37)$ & $7 \cdot 29(7 \cdot 19-7 \cdot 34)$ & $6 \cdot 40(4 \cdot 70-7 \cdot 75)$ & $5 \cdot 70(5 \cdot 03-6 \cdot 75)$ \\
2 & $151(138-162)$ & $34(30-38)$ & $7 \cdot 29(7 \cdot 21-7 \cdot 32)$ & $7 \cdot 40(6 \cdot 25-8 \cdot 33)$ & $5 \cdot 25(4 \cdot 94-7 \cdot 25)$ \\
6 & $151(139-161)$ & $35(28-36)$ & $7 \cdot 27(7 \cdot 22-7 \cdot 33)$ & $6 \cdot 80(5 \cdot 10-7 \cdot 80)$ & $5 \cdot 60(4 \cdot 91-6 \cdot 45)$ \\
200 mcg/kg loading dose & & & & \\
0 & $144(127-159)$ & $35(31-43)$ & $7 \cdot 33(7 \cdot 25-7 \cdot 35)$ & $8 \cdot 40(7 \cdot 10-9 \cdot 70)$ & $5 \cdot 25(4 \cdot 60-5 \cdot 80)$ \\
$0 \cdot 5$ & $142(127-153)$ & $33(27-39)$ & $7 \cdot 26(7 \cdot 19-7 \cdot 31)$ & $6 \cdot 30(5 \cdot 30-8 \cdot 30)$ & $6 \cdot 20(5 \cdot 70-6 \cdot 70)$ \\
2 & $137(130-144)$ & $35(29-40)$ & $7 \cdot 30(7 \cdot 26-7 \cdot 36)$ & $8 \cdot 50(6 \cdot 70-9 \cdot 45)$ & $5 \cdot 83(4 \cdot 53-6 \cdot 43)$ \\
6 & $135(123-144)$ & $33(29-43)$ & $7 \cdot 35(7 \cdot 28-7 \cdot 44)$ & $8 \cdot 20(7 \cdot 48-8 \cdot 73)$ & $5 \cdot 10(4 \cdot 50-6 \cdot 03)$ \\
\hline
\end{tabular}


Table 5 Behavioural and respiratory effort scores (0-30 minutes)

\begin{tabular}{lll}
\hline & $50 \mathrm{mcg} / \mathrm{kg}^{\star}$ & $200 \mathrm{mcg} / \mathrm{kg}$ \\
\hline Behavioural activity: & 9 & 12 \\
$\quad$ Unchanged & 3 & 1 \\
Increased/decreased & 9 & 7 \\
Respiratory effort: & 4 & 6 \\
Decreased & Unchanged/increased & 4 \\
\hline
\end{tabular}

$\star$ Behaviour score omitted in one infant. Differences between dosage groups not significant (Fisher's exact test).

and $1.14 \mathrm{~kg}$ ), and postnatal age (36 and 38 hours). One was receiving trigger ventilation when loading was begun. Following infusion of around two thirds of the loading dose, severe hypoxaemia and hypotension developed, managed by increasing ventilatory support, plasma infusion, and stopping the diamorphine. Both infants responded to these measures. One received intravenous naloxone and further opiate treatment was withheld.

Loading produced contrasting effects on behavioural activity, which remained unchanged in most infants, and respiratory effort, which was reduced in most infants (table 5). No significant differences in response were found between dosage groups. Three infants allocated to receive the lower loading dose were receiving trigger ventilation. Two continued to trigger successfully at completion of loading; the third developed a pneumothorax and was switched to intermittent positive pressure ventilation. In the higher loading dose group five infants received trigger ventilation at the start of treatment. Two of these infants (of 28 and 29 weeks' gestation) were changed to intermittent positive pressure ventilation during loading because of reduced triggering.

Nineteen of the 27 infants (10 in the lower loading dose group and nine in the higher loading dose group) received transfusions of blood or plasma during the 24 hours after starting diamorphine. Collection of blood samples over this period for stress hormone analysis and morphine pharmacokinetics was incomplete in five infants because of death (three infants) or discontinuation of sedation (two infants).

Baseline stress hormone concentrations did not differ significantly between dosage groups. At six hours both groups showed reductions in plasma catecholamine and cortisol concentrations (figure). The fall in adrenaline was significant in the lower loading dose group; falls in noradrenaline and cortisol were significant in the higher loading dose group. However, a comparison of the changes between groups showed no significant differences (table 6). From six to 24 hours stress hormones in the lower loading dose group showed further reductions, whereas in the higher loading dose group there was little or no further change in adrenaline and cortisol, and plasma noradrenaline concentrations increased.

Morphine and its major metabolites (M3G and M6G) were detected in the plasma samples of all study patients during the diamorphine infusion (table 7). The steadystate morphine concentration was lower, and was achieved more rapidly in the $200 \mathrm{mcg} / \mathrm{kg}$ loading dose group, but these differences were not significant. The times taken to achieve steady-state plasma concentrations for the two metabolites were noticeably longer than that for morphine. Morphine-3-glucuronide reached steady-state concentration after about 24 hours, but morphine-6-glucuronide had not reached a steady-state value even after 72 hours of diamorphine infusion.

The median durations of treatment with diamorphine were 63 and 48 hours in the lower and higher loading dose groups, respectively. After study entry intraventricular haemorrhage was diagnosed in six infants (two low dose, four high dose), pneumothorax in five infants (four low, one high), and bronchopulmonary dysplasia in 11 (six low, five high). Three deaths occurred before 14 days in both groups, with two further deaths from complications of prematurity between 28 days and six months in infants who received the higher loading dose.
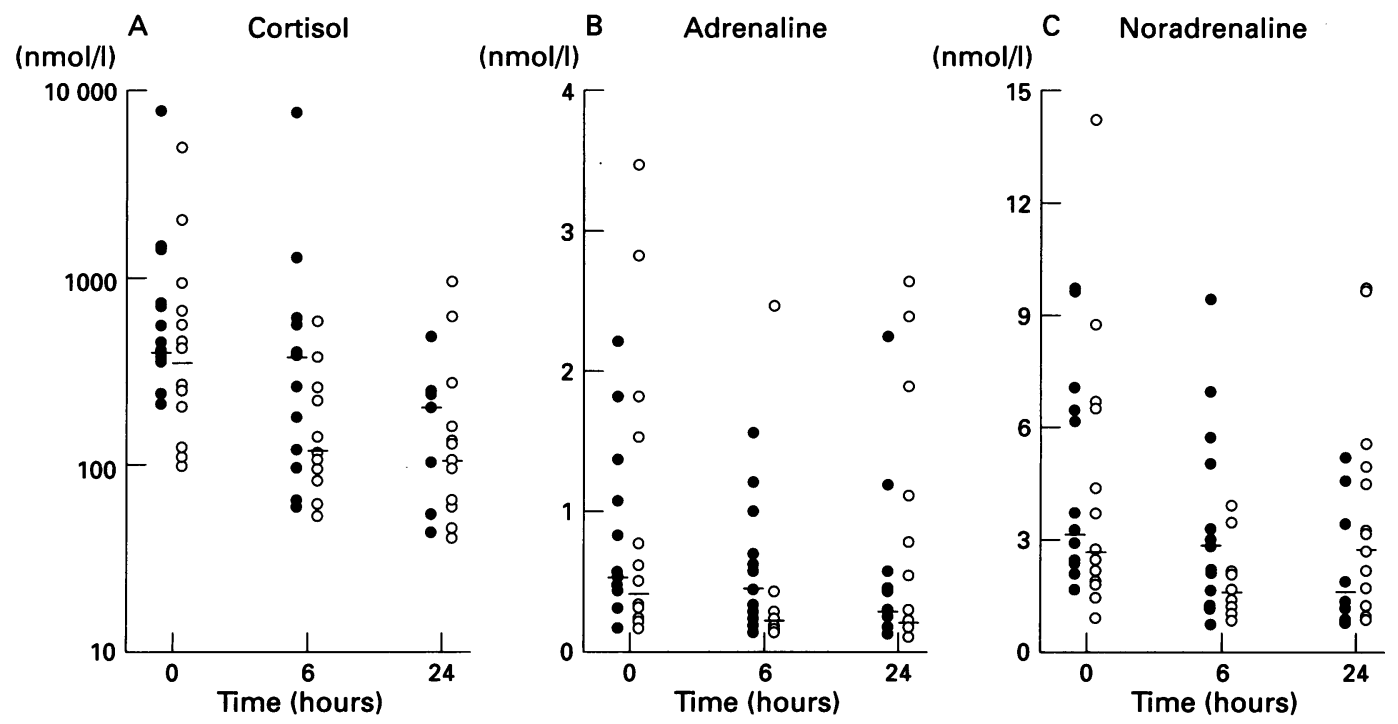

Stress hormone concentrations: ( $50 \mathrm{mcg} / \mathrm{kg}$ dose represented by closed circles, $200 \mathrm{mcg} / \mathrm{kg}$ dose by open circles; horizontal bar represents median values) 
Table 6 Change in plasma stress hormone concentrations (0-6 hours) showing median (interquartile range)

\begin{tabular}{|c|c|c|c|}
\hline & $50 \mathrm{mcg} / \mathrm{kg}$ loading dose & $200 \mathrm{mcg} / \mathrm{kg}$ loading dose & $\begin{array}{l}\text { Significance } \\
\text { (Mann-Whitney U test) }\end{array}$ \\
\hline $\begin{array}{l}\text { Adrenaline }(\mathrm{nmol} / \mathrm{l}) \\
\text { Noradrenaline }(\mathrm{nmol} / \mathrm{l}) \\
\text { Cortisol }\end{array}$ & $\begin{array}{l}-0.22(-0.06 \text { to }-0.37)^{\star \star \star} \\
-0.88(+0.21 \text { to }-1 \cdot 26) \\
-152(+11 \text { to }-209)\end{array}$ & $\begin{array}{l}-0.09(+0.06 \text { to }-0.83) \\
-0.93(-0.20 \text { to }-2.71)^{\star \star} \\
-111(-18 \text { to }-457)^{\star}\end{array}$ & $\begin{array}{l}\text { N/S } \\
\text { N/S } \\
\text { N/S }\end{array}$ \\
\hline
\end{tabular}

$\star \mathrm{P}<0.05, \star \star \mathrm{P}<0 \cdot 01, \star \star \star \mathrm{P}<0.005$ (Wilcoxon signed rank test).

\section{Discussion}

The importance of preventing and relieving pain and distress in sick newborn infants is now widely recognised. Preterm infants requiring mechanical ventilation undergo the most invasive procedures and are therefore most likely to benefit from analgesia. ${ }^{10}$ Opiates are commonly prescribed to provide analgesia and to improve synchrony during mechanical ventilation. To achieve a steady-state plasma concentration rapidly the administration of a loading dose is recommended, ${ }^{11}$ but the concentration of morphine which produces effective analgesia in neonates is not known precisely, and this contributes to a lack of uniformity in loading dose regimens. For morphine, a loading infusion of $100-200 \mathrm{mcg} / \mathrm{kg}$ intravenously over 30 minutes has been recommended for ventilated neonates. ${ }^{12}$ Levene and Quinn reported the use of a longer administration time of two hours. ${ }^{13}$ Rapid opiate administration may cause acute falls in blood pressure and arterial oxygenation. ${ }^{3}$

The small falls in blood pressure seen with diamorphine in this study are similar to those reported before. ${ }^{5}$ Mean blood pressure at the end of loading did not differ significantly between doses, but two infants receiving the higher dose became hypotensive as part of an acute clinical deterioration. These infants were below the median for gestation and birthweight, suggesting that smaller, more immature infants may be more likely to react adversely to a high loading dose than more mature infants.

Infusing $200 \mathrm{mcg} / \mathrm{kg}$ diamorphine intravenously over 30 minutes produced clinically important respiratory depression in infants with less severe respiratory disease at the time of starting treatment. Newborn infants are believed to be particularly sensitive to opiateinduced respiratory depression, ${ }^{14}$ though little information exists on the relation between dose and effect. Our data suggest that the effect on respiratory drive in ventilated infants of a $200 \mathrm{mcg} / \mathrm{kg}$ diamorphine bolus administered over 30 minutes is such that a compensatory increase in ventilatory support is likely to be required. Observations using a simple scoring

Table 7 Mean (1 SD) plasma concentrations of morphine, M3G, and M6G (ng/ml)

\begin{tabular}{|c|c|c|c|c|c|c|}
\hline \multirow{2}{*}{$\begin{array}{l}\text { Time } \\
\text { (hours) }\end{array}$} & \multicolumn{3}{|c|}{$50 \mathrm{mcg} / \mathrm{kg}$ loading dose } & \multicolumn{3}{|c|}{$200 \mathrm{mcg} / \mathrm{kg}$ loading dose } \\
\hline & Morphine & $M 3 G$ & $M 6 G$ & Morphine & $M 3 G$ & $M 6 G$ \\
\hline $\begin{array}{l}0 \\
0 \cdot 5 \\
2 \\
6 \\
12 \\
24 \\
48 \\
72\end{array}$ & $\begin{array}{c}0 \\
46(46) \\
52(56) \\
69(42) \\
72(40) \\
90(52) \\
118(39) \\
124(58)\end{array}$ & $\begin{array}{c}0 \\
5(13) \\
118(99) \\
290(263) \\
534(346) \\
800(376) \\
733(465) \\
646(474)\end{array}$ & $\begin{array}{l}0 \\
1(3) \\
3(5) \\
8(10) \\
16(15) \\
21(10) \\
48(25) \\
59(25)\end{array}$ & $\begin{array}{c}0 \\
50(28) \\
50(12) \\
44(25) \\
54(28) \\
51(31) \\
64(25) \\
65(40)\end{array}$ & $\begin{array}{c}0 \\
16(29) \\
211(285) \\
281(252) \\
414(331) \\
647(467) \\
547(338) \\
625(404)\end{array}$ & $\begin{array}{l}0 \\
1(3) \\
6(9) \\
11(11) \\
18(12) \\
27(13) \\
31(23) \\
45(37)\end{array}$ \\
\hline
\end{tabular}

system failed to detect a difference in respiratory effort between dosage groups at the end of loading. This was probably due to the relative insensitivity of the scoring system: distinguishing infants whose respirations are in close synchrony with the ventilator from those in whom chest movements are entirely ventilator driven is difficult. Behavioural observations confirmed the sensitivity of newborn infants to the respiratory depressant effects of diamorphine, as loading most commonly decreased respiratory effort without a concomitant effect on general behaviour. This is relevant to clinical practice, as body movements and responses to handling and procedures are often the prime measures used to guide decisionmaking during opiate treatment in the newborn. Lack of an effect on behaviour does therefore not necessarily indicate a lack of therapeutic effect.

Our data provide the first evidence of the efficacy of diamorphine in reducing the stress response in ventilated newborn infants. Reductions in plasma cortisol and catecholamines were most noticeable from zero to six hours, an interval during which little change could be accounted for by progression of illness, or changes in treatment - for example, introduction of inotropic agents. ${ }^{15} \mathrm{~A}$ longitudinal study of plasma cortisol in sick infants not treated with opiates found progressive increases over the first three days of life. ${ }^{16}$ Quinn et al reported that morphine started mainly in the first 12 hours after birth resulted in a significant reduction in plasma adrenaline, whereas infants receiving placebo showed no significant changes in catecholamines, ${ }^{1}$ high concentrations in the immediate postnatal period having subsided. Thus in the present study stress hormone concentration fell in both dosage groups at a time when in the absence of analgesia or sedation they would be expected to remain steady or to increase. At present it is not known whether reducing stress hormone concentrations in sick infants affects outcome. However, there is evidence from infants undergoing surgery that increased morbidity and mortality are associated with exaggerated stress responses. ${ }^{17}$ Further research into this area is needed.

The two major metabolites of morphine, M6G and M3G, have a major role in the pharmacological effects of morphine. Hence, in addition to morphine, the plasma concentrations of these active metabolites must be considered when discussing the overall therapeutic effect of diamorphine. The range of steady-state plasma morphine concentrations in this study was similar to those measured in a previous study. ${ }^{6}$ Surprisingly, morphine concentrations were generally higher in the infants 
treated with the lower loading dose, although this difference was not significant. Similar numbers of infants in both groups (six in the lower loading dose group and five in the higher loading dose group) had their infusion rates increased above $15 \mathrm{mcg} / \mathrm{kg} /$ hour within 24 hours of starting treatment.

The range of morphine concentrations seen in this study has been associated with successful pain alleviation, but at present there are insufficient data to state a therapeutic level for morphine metabolites in the premature infant. The mean steady-state $\mathrm{M} 6 \mathrm{G}$ and $\mathrm{M} 3 \mathrm{G}$ concentrations showed no significant differences between the two loading doses, and hence there was no evidence of any direct influence of the dosing regimen on these metabolite concentrations. The plasma M6G concentrations in both dosage groups never exceeded that of morphine; in adults the M6G concentration is significantly higher than morphine. ${ }^{18}$ This lower concentration of $\mathrm{M} 6 \mathrm{G}$ in preterm infants confirms previous studies of morphine administration which have shown low or undetectable plasma M6G concentrations. ${ }^{19-21}$ Reduced plasma M6G concentrations and slow accrual to steady-state may have important implications in the effectiveness of pain relief in infants, because M6G is acknowledged to have major analgesic action (equal to or greater than that of morphine). The plasma concentrations of $\mathrm{M} 3 \mathrm{G}$ measured in this study were much higher than those reported in previous studies after morphine administration in either preterm or term infants. ${ }^{1920}$ As $M 3 G$ is known to be an antagonist at the opiate receptor and can have an important stimulatory effect on respiration, ${ }^{22}$ this metabolite may also contribute to the overall therapeutic effect of the diamorphine infusion.

In conclusion, no significant differences were found between high and low loading doses of diamorphine in reducing stress hormone concentrations six hours after starting treatment, and the higher dose produced adverse physiological effects. In view of these results a loading dose of $200 \mathrm{mcg} / \mathrm{kg}$ diamorphine given intravenously over 30 minutes cannot be recommended. However, a loading dose of $50 \mathrm{mcg} / \mathrm{kg}$ diamorphine, followed by a continuous infusion of $15 \mathrm{mcg} / \mathrm{kg} /$ hour, seems to be both effective and safe.

1 Quinn MW, Wild J, Dean HG, Hartley R, Rushforth JA, Puntis JWL, et al. Randomised double-blind controlled trial of effect of morphine on catecholamine concentrations in ventilated preterm babies. Lancet 1993; 342: 324-7.

2 Pokela ML. Effect of opioid-induced analgesia on betaendorphin, cortisol and glucose responses in neonate with cardiorespiratory problems. Biol Neonate 1993; 64: 360-7.
Appendix 1

Behaviour score ${ }^{\star}$ :

1 Constant distress, continuous movements and resistance to ventilation

2 Frequent periods of distress, spontaneous or in response to light handling

3 Occasional periods of distress, spontaneous or in response to light handling

4 Quiet unless disturbed suction

Respiratory effort score:

1 Irregular respiration, totally asynchronous with ventilator

2 Mainly asynchronous, occasionally in phase with ventilator

3 Chest movement mainly synchronous, occasionally out of phase

4 Chest movement continuously synchronous with ventilator

${ }^{\star}$ Modified from Chay et al 1992. ${ }^{11}$

3 Marlow N, Weindling AM, Cooke RWI. Hazards of analgesia for newborn infants. Arch Dis Child 1988; 63 1293.

4 Rutter N, Richardson J. A survey of the use of analgesia in newborn intensive care. Int $\mathcal{F}$ Pharm Pract 1992; 1: 220-2.

5 Elias-Jones AC, Barrett DA, Rutter N, Shaw PN, Davis SS. Diamorphine infusion in the preterm neonate. Arch Dis Child 1991; 66: 1155-7.

6 Barrett DA, Elias-Jones AC, Rutter N, Shaw PN, Davis SS Morphine kinetics after diamorphine infusion in premature neonates. Br f Clin Pharmacol 1991; 32: 31-7.

7 Moore A, Aitken R, Burke C, Gaskell S, Groom G, Holder $\mathrm{G}$, et al. Cortisol assays: guidelines for the provision of a clinical biochemistry service. Ann Clin Biochem 1985; 22 435-53.

8 McDonald IA, Lake DM. An improved technique for extracting catecholamines from body fluids. $\mathcal{F}$ Neuroscl Methods 1985; 13: 239-48.

9 Pawula M, Barrett DA, Shaw PN. An improved extraction method for the HPLC determination of morphine and its metabolites in plasma. F Pharm Biomed Anal 1993; 11: 401-6.

10 Barker DP, Rutter N. Exposure to invasive procedures in neonatal intensive care unit admissions. Arch Dis Child 1995; 72: F47-8.

11 Chay PCW, Duffy BJ, Walker JS. Pharmacokinetic-pharmacodynamic relationships of morphine in neonates. Clin macodynamic relationships of mor

12 Treating moderate and severe pain in infants. Drug and Therapeutics Bulletin 1994; 32: 21-4.

13 Levene MI, Quinn MW. Use of sedatives and muscle relaxants in newborn babies receiving mechanical ventilation. Arch Dis Child 1992; 67: 870-3.

14 Way WL, Costley EC, Way EL. Respiratory sensitivity of the newborn infant to meperidine and morphine. Clin Pharmacol Ther 1965; 6: 454-61.

15 Stopfkuchen H, Racke K, Schwörer H, Queisser-Luft A, Vogel $\mathrm{K}$. Effects of dopamine infusion on plasma catecholamines in preterm and term newborn infants. Eur $\mathcal{f}$ Pediatr 1991; 150: 503-6.

16 Hughes D, Murphy JF, Dyas J, Robinson JA, Riad-Fahmy D, Hughes IA. Blood spot glucocorticoid concentrations D, Hughes IA. Blood spot glucocorticoid concentrations

17 Anand KJS, Sippell WG, Aynsley-Green A. Randomised trial of fentanyl anaesthesia in preterm babies undergoing surgery: effects on the stress response. Lancet 1987; i 243-8.

18 Osborne R, Joel S, Trew D, Slevin M. Morphine and metabolite behaviour after different routes of morphine administration: demonstration of the importance of the active metabolite morphine-6-glucuronide. Clin Pharmacol Ther 1990; 47: 12-9.

19 Hartley R, Quinn M, Green M, Levene MI. Morphine glucuronidation in premature neonates. Br $\mathcal{F}$ Clin Pharmacol 1993; 35: 314-7.

20 Choonara IA, McKay P, Hain R, Rane A. Morphine metabolism in children. Br $\mathcal{f}$ Clin Pharmacol 1989; 28: 599-604.

21 Bhat R, Chari G, Gulati A, Aldana O, Velamati R, Bhargava H. Pharmacokinetics of a single dose of morphine in preterm infants during the first week of life. $\mathcal{F}$ Pediat 1990; 117: 477-81.

22 Gong Q-L, Hedner T, Hedner J, Bjorkman R, Nordberg G. Antinociceptive and ventilatory effects of the morphine metabolites: morphine-6-glucuronide and morphine-3glucuronide. Eur fु Pharmacol 1991; 193: 47-56. 